\title{
Rapid, accurate, and quantitative detection of propranolol in multiple human biofluids via surface-enhanced Raman scattering
}

\begin{abstract}
Abdu Subaihi ${ }^{1}$, Laila Almanqur $^{1}$, Howbeer Muhamadali ${ }^{1}$, Najla AlMasoud ${ }^{1}$, David I. Ellis ${ }^{1}$, Drupad K Trivedi ${ }^{1}$, Katherine A. Hollywood ${ }^{2}$ Yun $\mathrm{Xu}^{1}$ and Royston Goodacre ${ }^{1 *}$

${ }^{1}$ School of Chemistry, Manchester Institute of Biotechnology, University of Manchester, 131 Princess Street, Manchester, M1 7DN, UK

${ }^{2}$ Faculty of Life Sciences, Manchester Institute of Biotechnology, University of Manchester, 131 Princess Street, Manchester, M1 7DN, UK.
\end{abstract}

*Corresponding author: E-mail: roy.goodacre@manchester.ac.uk

Table S1 LC-MS solvent gradient for reverse phase analysis

\begin{tabular}{|c|c|c|c|}
\hline $\begin{array}{c}\text { Time } \\
(\mathbf{m i n})\end{array}$ & $\begin{array}{c}\text { Flow Rate } \\
\left(\boldsymbol{\mu L} \mathbf{~ m i n}^{-\mathbf{1}}\right)\end{array}$ & $\begin{array}{c}\text { Mobile Phase A } \\
\left(\mathbf{H}_{\mathbf{2}} \mathbf{O} \%\right)\end{array}$ & $\begin{array}{c}\text { Mobile Phase B } \\
(\mathbf{M e O H})\end{array}$ \\
\hline 0 & 400 & 80 & 20 \\
\hline 1 & 400 & 80 & 20 \\
\hline 4 & 400 & 5 & 95 \\
\hline 6 & 400 & 5 & 20 \\
\hline 7 & 400 & 80 & \\
\hline
\end{tabular}

Table S2 Assignments of serum peaks labelled in Figure 2. ${ }^{1-3}$

\begin{tabular}{|c|c|c|}
\hline Band $\left.\mathbf{( c m}^{\mathbf{- 1}}\right)$ & Vibrational mode & Assignment \\
\hline 632 & C-S stretch & Tyrosine \\
\hline 723 & C-H bending & Adenine \\
\hline 810 & Ring breathing & Tyrosine \\
\hline 959 & C-C & $\alpha$-Helix, proline, valine \\
\hline 1096 & C-N & D-Mannose \\
\hline 1132 & C-N & D-Mannose \\
\hline 1204 & Ring vibration & Phenylalanine, tryptophan \\
\hline 1330 & - & Amide III \\
\hline 1446 & $\mathrm{CH}_{2}$ bending & Collagen, lipids \\
\hline 1583 & - & Tryptophan, phenylalanine \\
\hline 1696 & - & Amide I \\
\hline
\end{tabular}


Table S3 Assignments of plasma peaks labelled in Figure 2. ${ }^{3,4}$

\begin{tabular}{|c|c|c|}
\hline Band $\left.\mathbf{( c m}^{-\mathbf{1}}\right)$ & Vibrational mode & Assignment \\
\hline 491 & Ring vibration & Cellulose, guanine, L-arginine \\
\hline 590 & - & Ascorbic acid, amide-VI \\
\hline 634 & $\mathrm{C}-\mathrm{S}$ & L-Tyrosine, \\
\hline 725 & $\mathrm{C}-\mathrm{H}$ & Adenine \\
\hline 810 & $\mathrm{C}-\mathrm{C}-\mathrm{O}$ & L-Serine, glutathione \\
\hline 885 & $\mathrm{C}-\mathrm{O}-\mathrm{H}$ & $\begin{array}{c}\text { Glutathione, } \\
\text { D-(C)-galactosamine }\end{array}$ \\
\hline 1012 & & Phenylalanine \\
\hline 1074 & $\mathrm{C}-\mathrm{C}$ & Collagen \\
\hline 1132 & $\mathrm{C}-\mathrm{N}$ & D-Mannose \\
\hline 1209 & $\mathrm{C}-\mathrm{N}$ & L-Tryptophan, phenylalanine \\
\hline 1358 & Ring vibration & Tryptophan, adenine, guanine \\
\hline 1448 & - & Collagen, phospholipids \\
\hline 1580 & $\mathrm{CH}$ & $\begin{array}{c}\text { Phenylalanine, acetoacetate, } \\
\text { riboflavin }\end{array}$ \\
\hline 1684 & $\mathrm{C}-\mathrm{C}$ & $\alpha-$ Helix, collagen \\
\hline & $\mathrm{C}=\mathrm{O}$ &
\end{tabular}

Table S4 Assignments of urine peaks labelled in Figure 2. ${ }^{5-8}$

\begin{tabular}{|c|c|c|}
\hline Band $\left(\mathbf{c m}^{-\mathbf{1}}\right)$ & Vibrational mode & Assignment \\
\hline 658 & C=O-N deformation & Uric acid \\
\hline 713 & C-H stretching & Hypoxanthine \\
\hline 804 & C-C stretching & Amino acid \\
\hline 1002 & C-N stretching & Phenylalanine \\
\hline 1133 & C-N stretching & Uric acid \\
\hline 1218 & Ring vibration & Phenylalanine \\
\hline 1350 & C-H deformation & Adenine \\
\hline 1448 & - & Tryptophan \\
\hline 1582 & ring stretches & Phenylalanine \\
\hline
\end{tabular}




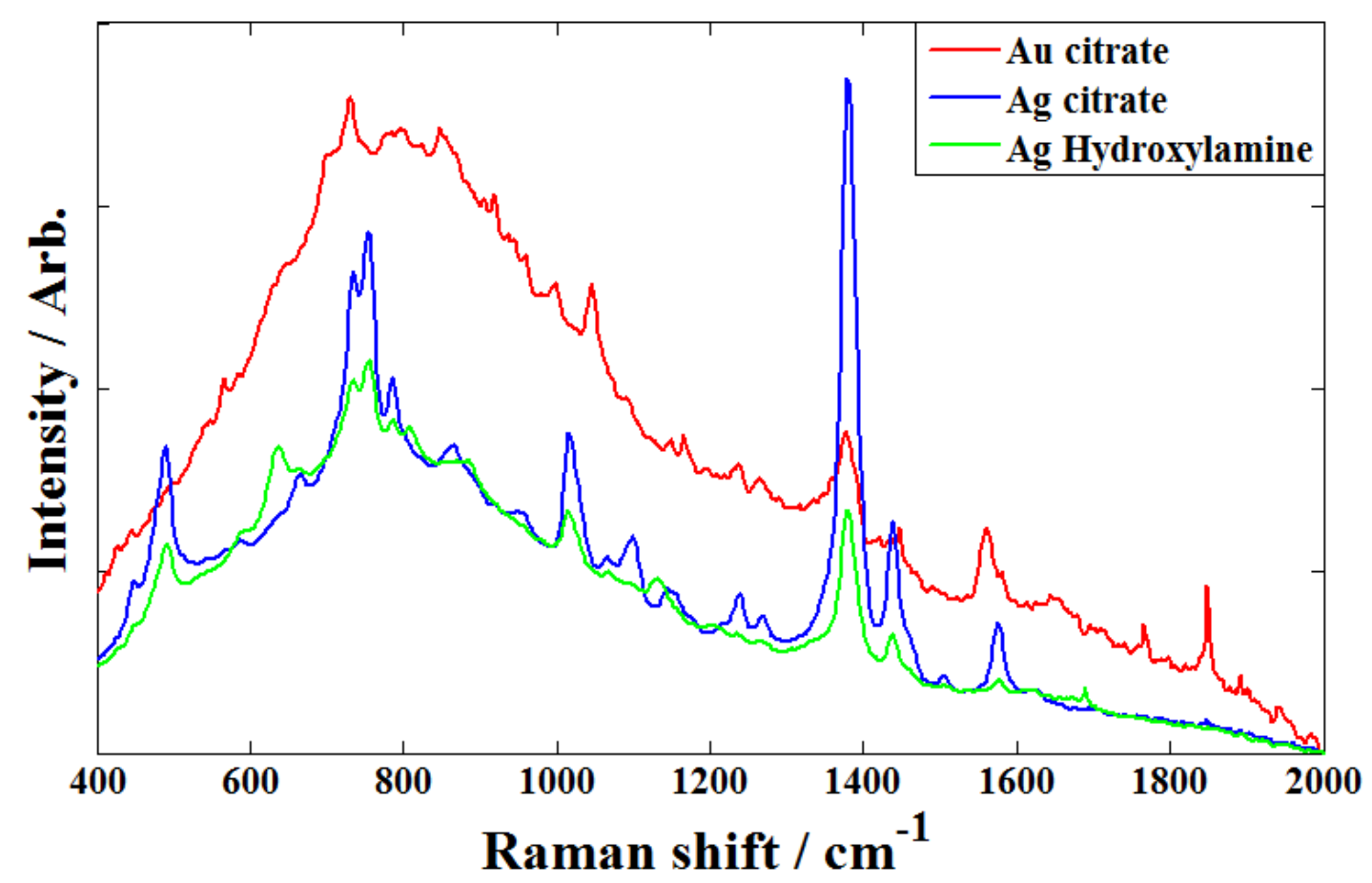

Figure S1 Plot shows SERS spectra of using different nanoparticles (Au citrate, Ag citrate and Ag hydroxylamine) in conjunction with $200 \mu \mathrm{M}$ of propranolol spiked into filtered plasma.

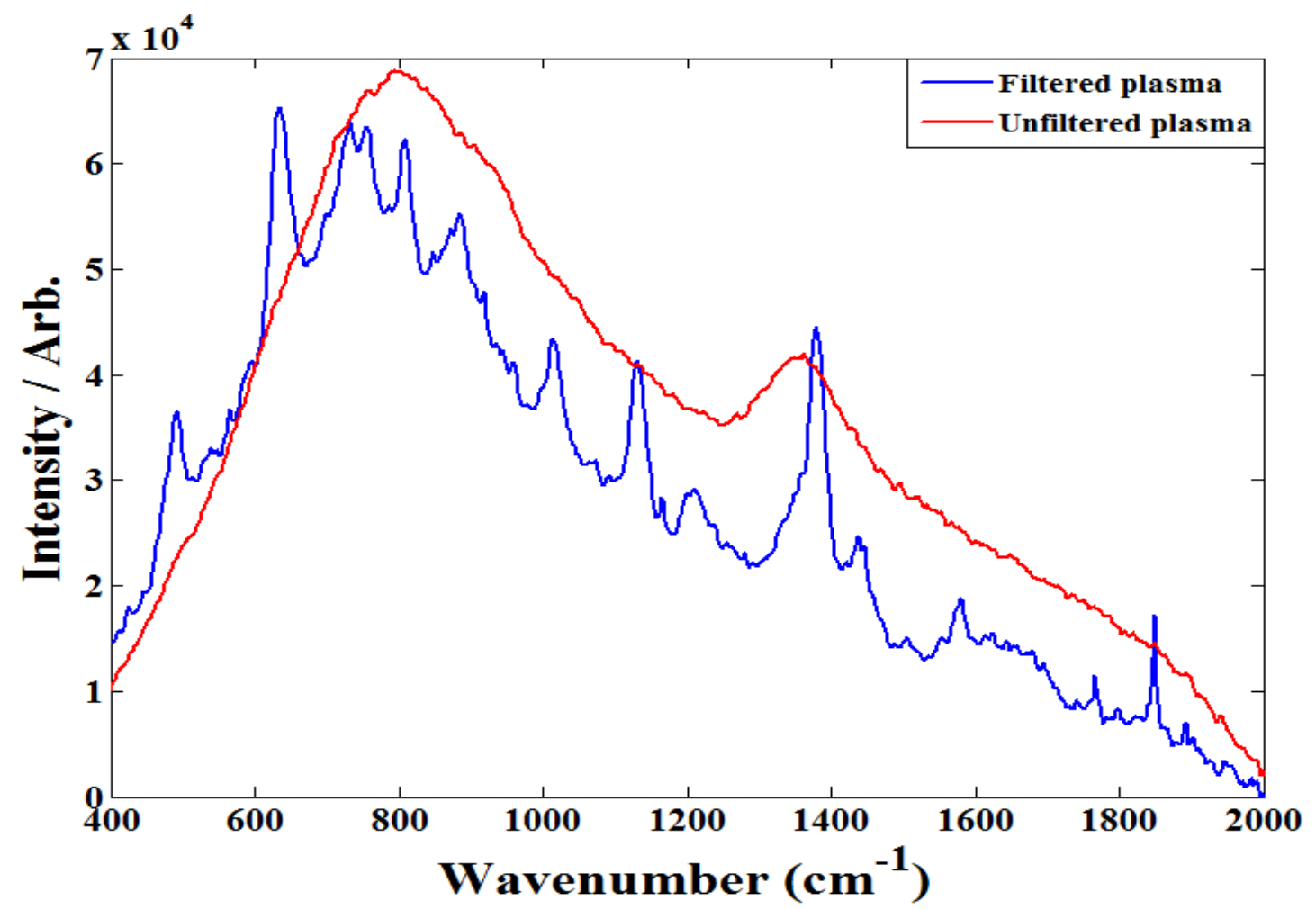

Figure S2 Plot shows SERS spectra of filtered and unfiltered plasma spiked with $0.5 \mathrm{mM}$ propranolol. 

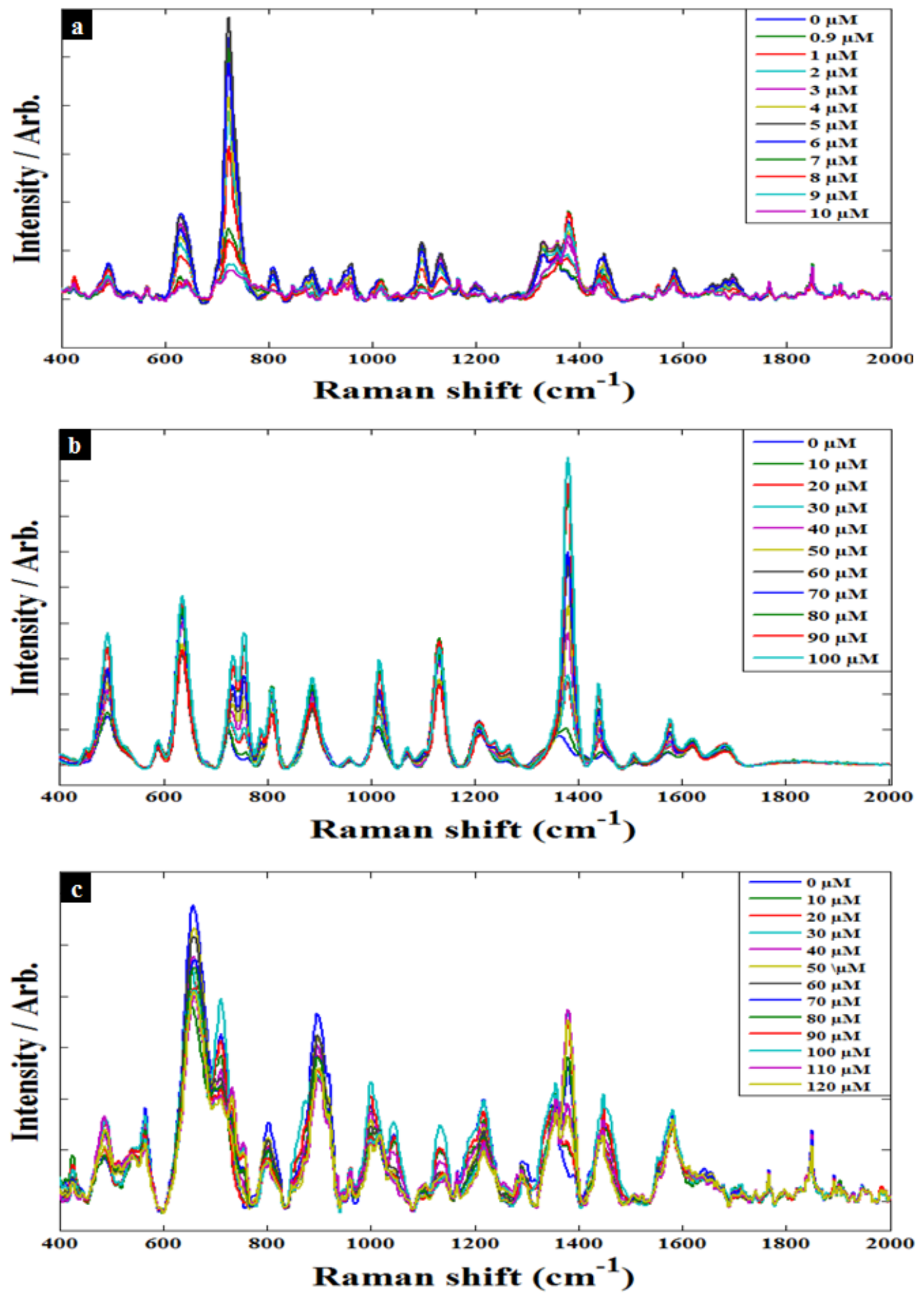

Figure S3. SERS spectra illustrate the different concentrations of propranolol spiked into biofluids: (a) serum, (b) plasma, and (c) urine 

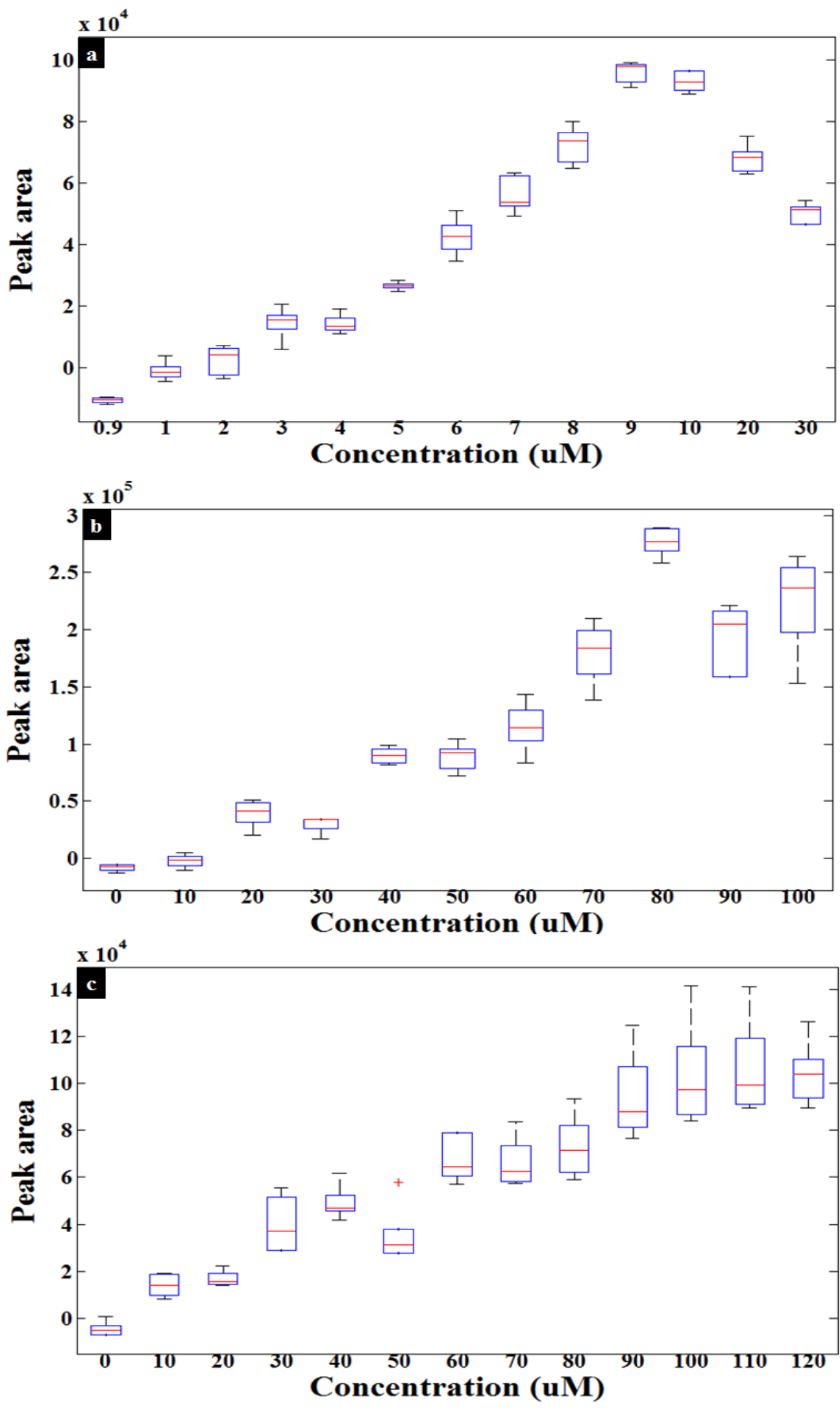

Figure S4. Box and Whisker plots of the area under the peak at $1381 \mathrm{~cm}^{-1}$ versus propranolol concentrations spiked into the following human biofluids: (a) serum, (b) plasma, and (c) urine. These data are from five replicates where the red line represents the median value, the blue box the interquartile range, the error bars the $95 \%$ confidence region and the red crosses any outliers. Note in (a \& c) that the $\mathrm{x}$-axis is not plotted to scale. 


\section{SERS of propranolol spiked in plasma before the pre-filtration step}
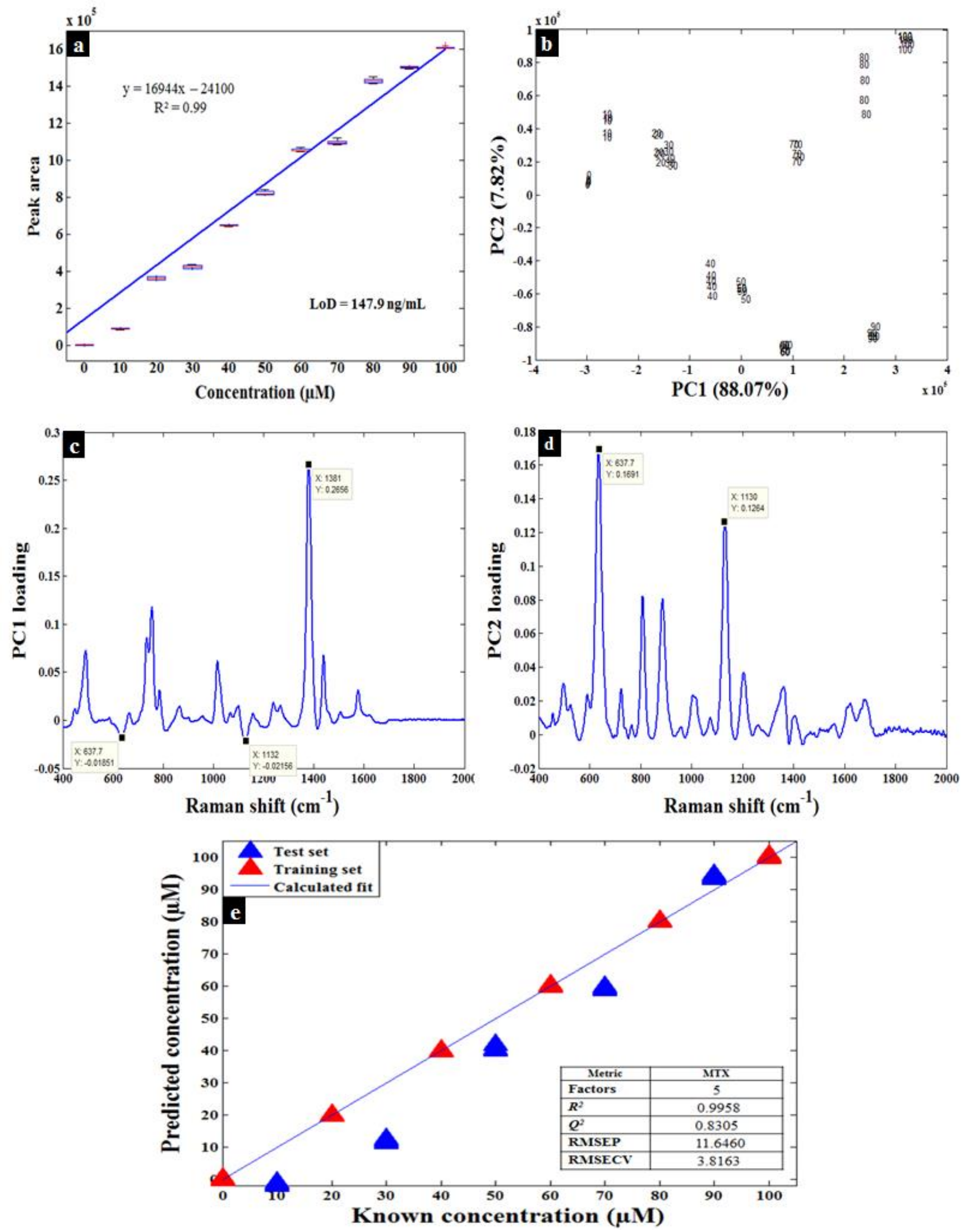

Figure S5. (a) Plot of the area under the peak at $1381 \mathrm{~cm}^{-1}$ versus propranolol concentrations spiked into plasma before filtration. (b) PCA and loadings plots of (c) PC1 and (d) PC2. (e) PLSR 


\section{SERS of propranolol spiked in plasma after the pre-filtration step}
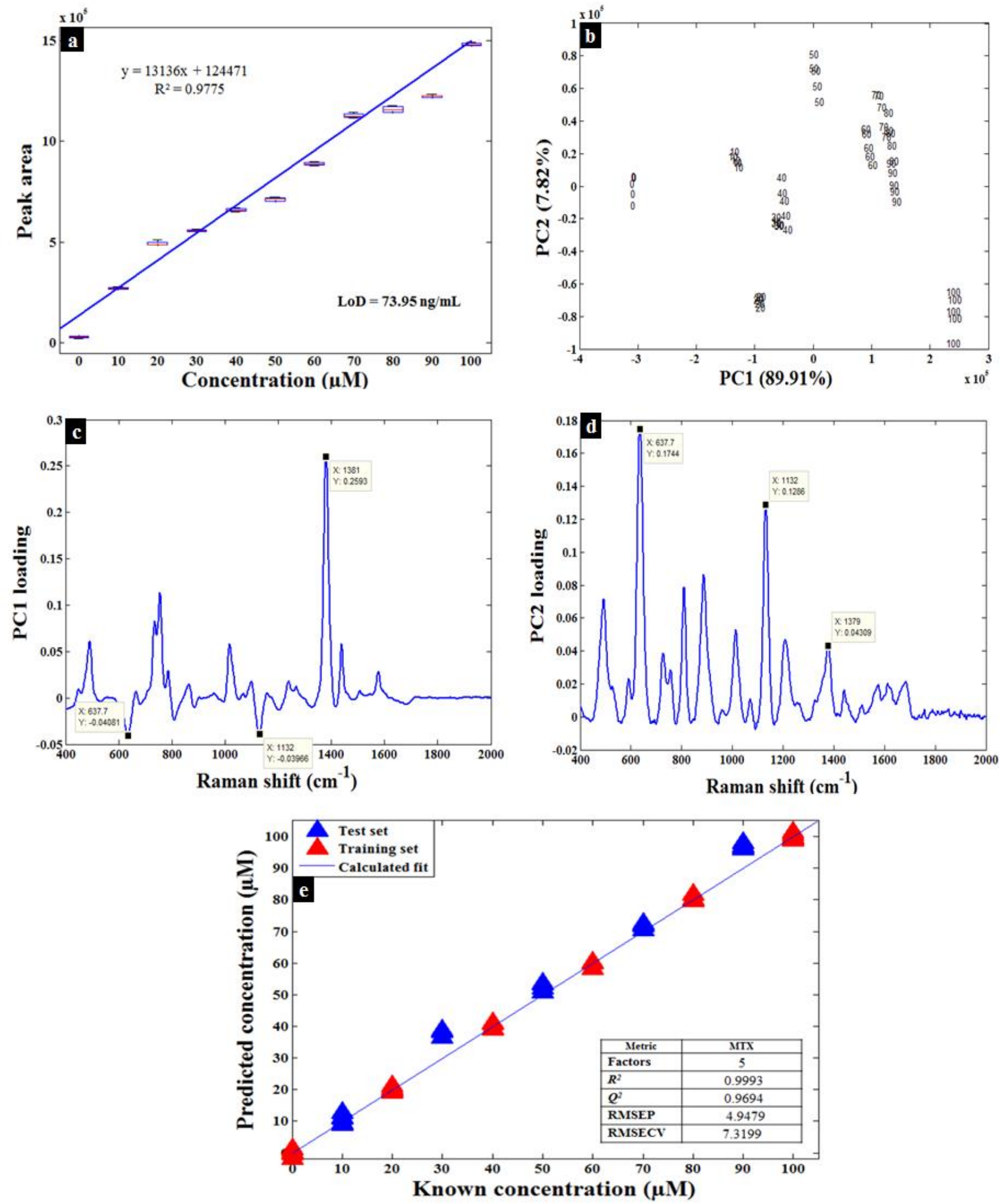

Figure S6. (a) Plot of the area under the peak at $1381 \mathrm{~cm}^{-1}$ versus propranolol concentrations spiked into plasma after filtration. (b) PCA and loadings plots of (c) PC1 and (d) PC2. (e) PLSR 


\section{REFERENCES}

(1) Wang, J.; Lin, D.; Lin, J.; Yu, Y.; Huang, Z.; Chen, Y.; Lin, J.; Feng, S.; Li, B.; Liu, N. Journal of biomedical optics 2014, 19, 087003-087003.

(2) Li, X.; Yang, T.; Li, S.; Zhang, S.; Jin, L. Appl. Phys. B 2015, 119, 393-398.

(3) Han, H.; Yan, X.; Dong, R.; Ban, G.; Li, K. Appl. Phys. B 2009, 94, 667-672.

(4) Feng, S.; Chen, R.; Lin, J.; Pan, J.; Chen, G.; Li, Y.; Cheng, M.; Huang, Z.; Chen, J.; Zeng, H. Biosensors Bioelectron. 2010, 25, 2414-2419.

(5) Dong, R.; Weng, S.; Yang, L.; Liu, J. Anal. Chem. 2015, 87, 2937-2944.

(6) Del Mistro, G.; Cervo, S.; Mansutti, E.; Spizzo, R.; Colombatti, A.; Belmonte, P.; Zucconelli, R.; Steffan, A.; Sergo, V.; Bonifacio, A. Anal. Bioanal. Chem. 2015, 407, 32713275.

(7) Premasiri, W. R.; Clarke, R. H.; Womble, M. E. Lasers Surg. Med. 2001, 28, 330-334.

(8) Huang, S.; Wang, L.; Chen, W.; Feng, S.; Lin, J.; Huang, Z.; Chen, G.; Li, B.; Chen, R. Laser Physics Letters 2014, 11, 115604. 